\title{
AIAA 2000-0576 \\ Diffusive-thermal instability of counterflow flames at low Lewis number
}

Carsten Kaiser, Jian-Bang Liu, Paul D. Ronney

Department of Aerospace and Mechanical Engineering, University of Southern California, Los Angeles, CA 90089-1453

$38^{\text {th }}$ Aerospace Sciences Meeting \& Exhibit $10-13$ January 2000 Reno, Nevada 


\title{
DIFFUSIVE-THERMAL INSTABILITY OF COUNTERFLOW FLAMES AT LOW LEWIS NUMBER
}

\author{
Carsten Kaiser, Jian-Bang Liu and Paul D. Ronney \\ Department of Aerospace and Mechanical Engineering \\ University of Southern California, Los Angeles, CA 90089-1453
}

\begin{abstract}
$\underline{\text { Abstract }}$
The effects of hydrodynamic strain on diffusivethermal instabilities at low Lewis number were studied experimentally using a counterflow slot-jet apparatus with $\mathrm{H}_{2}-\mathrm{O}_{2}-\mathrm{N}_{2}$ mixtures. Three configurations were examined: single premixed, twin premixed and nonpremixed flames. For all three configurations a wide variety of nonplanar flame structures were observed. Two extinction limits, one at very high strain (corresponding to a residence time limitation) and one at low strain (corresponding to a heat loss extinction) were found. For premixed flames, nonplanar structures occurred for a wide range of mixtures. In many cases, near extinction the flame structures reduced to a single "flame tube" elongated in the direction of extensional strain. An examination of stoichiometry effects revealed a critical equivalence ratio for instability similar to that known to exist for flame balls. At low flow velocities a transition to flames attached to the jet exits in complicated ways was noted, and at high flow velocities transition to turbulent flow was noted. For nonpremixed flames, nonplanar flame structures were observed only for near-extinction conditions, but the resulting flame shapes were quite similar to those of premixed flames. These results are compared to recent theoretical predictions.
\end{abstract}

\section{Introduction}

It is well known theoretically and experimentally that both premixed flames $e^{1,2,3,4,5,6}$ and nonpremixed flames $^{7,8,9}$ exhibit diffusive-thermal instability (DTI) that leads to cellular flame structures at low Lewis number (Le) of the stoichiometrically limiting reactant (fuel or oxidant). Here Le is defined as the ratio of the thermal diffusivity of the bulk mixture to the mass diffusivity of the reactant. It is also well established theoretically that flame stretch due to hydrodynamic strain or front curvature affects these instabilities. ${ }^{10,11,12,13,14,15,16}$ Stretch effects on low-Le DTI is relevant to turbulent combustion of lean mixtures of light fuels such as hydrogen and methane, since the low-Le DTI is known to affect the wrinkling characteristics and burning rates of turbulent flames in these fuels, ${ }^{17,18}$ and moreover the strain and front curvature induced by turbulence will affect these wrinkling characteristics.

This paper describes experimental studies of the effects of stretch on low-Le diffusive-thermal instabilities. These experiments are compared to existing theoretical predictions and the few prior experimental works, and may perhaps motivate additional theoretical works. A subsequent paper of ours will describe the high-Le DTI of stretched flames, which is relevant to turbulent combustion of lean mixtures of heavy hydrocarbons such as gasoline, thus all discussion of flame behavior at Le > 1 will be deferred to that work.

Theory predicts varied effects of flame stretch on low-Le DTI. The strength of the stretch effect is typically characterized by a Damkhler number (Da), which indicates the ratio of the stretch rate to a characteristic chemical reaction rate of the mixture at unstretched conditions. For flames with chemistry that can be approximated by one-step Arrhenius kinetics, $\mathrm{Da}$ can be defined as

$$
D a \equiv \frac{A e^{-\beta}}{\sigma}
$$

where $\mathrm{A}$ is an appropriately chosen pre-exponential factor, ${ }^{12,15,16} \quad \beta \equiv \mathrm{E} / \mathrm{RT}_{\mathrm{ad}}$ is the non-dimensional activation energy, $\mathrm{E}$ the activation energy, $\mathrm{R}$ the gas constant, $\mathrm{T}_{\mathrm{ad}}$ the adiabatic flame temperature, and $\sigma$ the stretch rate. For unstretched $(\mathrm{Da}=)$ premixed flames, DTI is predicted to occur for all mixtures having sufficiently low Le of the stoichiometrically limiting reactant. ${ }^{3}$ Heat losses are predicted to widen the range of Le for which DTI occurs. ${ }^{19}$ Sivashinsky et al. ${ }^{10}$ and Buckmaster and Ludford ${ }^{20}$ showed that Flame stretch due to extensional hydrodynamic strain can suppress the instability. ${ }^{10,20}$ Matalon and Erneux ${ }^{11}$ showed that the curvature of expanding spherical flames, which are stretched in a similar manner, also suppresses the instability. All of these theoretical results were obtained for the case of Near-Equidiffusional Flames (NEFs), in which the departure of Le from unity is small, that is, the quantity $\beta(\mathrm{Le}-1)$ is an order unity quantity in the asymptotic limit $\beta \rightarrow$. Computational studies have extended these results to cases where Le is not close to unity. Buckmaster and Short ${ }^{12}$ and Daou and Lin ${ }^{16}$ showed that for stretched flames in a counterflow straining configuration, for sufficiently low Le the instability will occur for all values of Da down to and below the extinction value." In such cases, at low $\mathrm{Da}$ (close to the extinction limit)

\footnotetext{
*It is not clear whether a value of Le exists at which cells occur at low strain, are suppressed at moderate strain, and reappear at high strain. We will show that this occurs experimentally, but only because of heat losses, which were not considered by Buckmaster and Short ${ }^{12}$ and Daou and Lin. 16
} 
the flame structure becomes discontinuous, resulting in flame tubes ${ }^{* *}$ elongated in the direction of extensional strain, which enables the flame to survive in the presence of strain that would cause it to extinguish were it forced to remain planar or moderately wrinkled. In essence, the weakening of the flame by strain is taken to an extreme condition for which it cannot survive without the intensification caused by curvature. Buckmaster and Short ${ }^{12}$ predicted an infinite chain of tubes for moderately low Da, then one or two isolated stationary tube(s) at progressively lower Da. Yet lower Da causes complete flame extinguishment. Daou and Lin ${ }^{16}$ predicted single flame tubes, but did not specifically report the other structures noted by Buckmaster and Short. ${ }^{12}$ It is interesting to note that these structures occur at values of Da that are lower than the value corresponding to extinction of plane flames. This behavior is somewhat analogous to sphericallysymmetric flame balls observed in microgravity experiments ${ }^{21}$ where in that case radiative transfer rather than extensional strain is the prevailing loss mechanism, but in both cases, at low Le enhancement of flame temperature causes the curved flame to survive where a plane flame could not, and moreover the loss mechanism prevents the flame from being able to grow in size. According to Buckmaster and Short's calculations, $^{12}$ flame tubes can survive at values of Da at least 2.9 times lower than the extinction value for strained plane flames in mixtures with $\mathrm{Le}=0.3$ and $\beta$ $=16$. The corresponding values predicted by Daou and Lin ${ }^{16}$ are 1.9 times lower for Le $=0.375$ and $\beta=8$.

It should be noted that while steady spherical flame balls in an infinite domain are possible in which heat and mass transport occur only via diffusion, ${ }^{22}$ the corresponding solution in cylindrical geometry does not exist because of the logarithmic singularity at infinite radius. Buckmaster and Short showed, however, that the addition of extensional strain removes this singularity and thus in principle should allow steady cylindrical flame structures to exist.

Theory, $^{23}$ computation $^{24}$ and experiment ${ }^{25}$ show that for convection-free flame balls, transition from fuel-lean burning to fuel-rich burning at the surface of a flame ball occurs not at a global mixture equivalence ratio $(\phi)$ of unity as in planar flames ${ }^{26}$ but rather at $\phi=\phi_{\mathrm{c}} \equiv \mathrm{Le}_{\mathrm{fu}} / \mathrm{Le}_{\mathrm{ox}}$, where the subscripts fu and ox refer to fuel and oxidant, respectively. Hence, when $\phi$ is significantly less than (greater than) $\phi_{\mathrm{c}}$, the fuel (oxidant) is the deficient reactant for the purposes of determining the effective Le. As a consequence, significant changes in flame ball behavior are predicted near $\phi=\phi_{c}$, with no significant change near $\phi=1$. No analyses have been conducted to determine whether

\footnotetext{
${ }^{* *}$ While Buckmaster and Short $^{12}$ use the term flame strings, Daou and Lin ${ }^{16}$ use the term spots, and Thatcher et al. ${ }^{14}$ use the term flame strips, we prefer the term flame tubes to emphasize that chemical reaction occurs primarily on the surface of the structure.
}

similar behavior occurs for flame tubes, or if instead the convection influences critical for establishing steady flame tubes cause them to behave more akin to planar flames than flame tubes in this regard.

There are few experimental observations on premixed flames that might be compared to these theoretical predictions. Ishizuka et $a$. $^{27}$ and Ishizuka and $\mathrm{Law}^{28}$ examined lean methane-air and rich propaneair mixtures in a counterflow, but these mixtures have Lewis numbers only slightly less than unity (about 0.95 and 0.80 respectively), and were not found to exhibit the wide range of structures described above. Indeed, for these mixtures with near-unity Le, the effect of stretch was shown to be merely to suppress cellular instability, in accordance with the NEF model predictions. Very recent experiments ${ }^{29}$ suggest the occurrence of single tube-like flame structures for lean $\mathrm{H}_{2}$-air mixtures (Le ${ }^{-} 0.30$ ) at low $\mathrm{Da}$ (very near extinction limits) in a slot-jet counterflow apparatus. In contrast, no similar behavior was observed in lean $\mathrm{CH}_{4}-\mathrm{O}_{2}-\mathrm{CO}_{2}$ mixtures (Le ${ }^{-} 0.86$ ); instead cellular flames were exhibited at high $\mathrm{Da}$ but cells were suppressed at lower $\mathrm{Da}$, in agreement with the aforementioned NEF predictions. This influence of Le is consistent with Buckmaster and Short, ${ }^{12}$ who predicted flame tubes at Le $=0.3$ but not Le $=0.5$, and Daou and Lin, ${ }^{16}$ who predicted flame tubes for Le = $1 / 2$ but not $\mathrm{Le}=5 / 8$. In contrast, for unstrained flames cellular structures are predicted to occur below Le $=1$ $2 / \beta{ }^{3}$ which corresponds to Le $=0.875$ and Le $=0.75$, respectively, for the parameters assumed in Buckmaster and Short and in Daou and Lin. Thus both experiments and theory seem to show that flame-tube behavior occurs only at sufficiently low Le, i.e., well below the critical value for the occurrence of cellular flames, and lower than those attainable from lean $\mathrm{CH}_{4}$ air, lean $\mathrm{CH}_{4}-\mathrm{O}_{2}-\mathrm{CO}_{2}$, or rich $\mathrm{C}_{3} \mathrm{H}_{8}$-air mixtures. For these mixtures with Le only moderately less than unity, stretch only acts to suppress instabilities rather than trigger new ones.

For nonpremixed flames, the behavior predicted by theory is quite different from that of premixed flames. DTI can occur only at low values of Da near extinction conditions because at higher $\mathrm{Da}$, the structure of the nonpremixed flame sheet is determined only by mixing considerations without coupling to chemical reaction. Under such conditions the flame is unconditionally stable. ${ }^{9} \quad$ At sufficiently low $\mathrm{Da}$, reactant leakage through the flame front occurs ${ }^{30}$ which causes partial premixing of reactants and thus the local heat release rate becomes dependent on chemical reaction rates in addition to mixing rates. This in turn enables a diffusive-thermal instability to occur for both the socalled diffusion flame regime of nonpremixed flames $^{9,31}$ in which an $\mathrm{O}(1 / \beta)$ amount of both reactants leak through the flame front, as well as the premixed flame regime of nonpremixed flames ${ }^{32}$ in which an $\mathrm{O}(1)$ amount of one reactant leaks though the flame 
front. Similar results are predicted for both the theoretically-attractive convective diffusion flame $e^{9,31}$ and the experimentally-convenient strained counterflow configuration. ${ }^{13,32}$ These models, as well as experiments $^{8}$ show that for the low-Le DTI to occur, not only must Da be sufficiently low, but also the Lewis number must be sufficient small. ${ }^{* * *}$ The experiments $^{8}$ also showed that similar results are obtained if the driving mechanism for extinction is heat loss (which occurs at very low stretch rates or high Da, as discussed later) rather than finite residence time at low Da, though no theoretical predictions of the effect of heat loss on cellular nonpremixed flames have been reported.

As with premixed flames, flame tubes have been predicted for nonpremixed flames. Computations by Thatcher et al. ${ }^{14}$ indicate that for $\beta=10$ and equal Lewis numbers of fuel and oxidant, a Lewis number of less than about 0.50 is required to observe the onset of tube-like behavior. A sequence of behavior very similar to premixed flames was predicted as Da was reduced: plane flames, an array of flame tubes, isolated flame tubes and finally extinction. In contrast, Daou and Lin ${ }^{15}$ did not predict any flame tube behavior even with $\mathrm{Le}_{\mathrm{Fu}}$ as low as 3/8 when $\mathrm{Le}_{\mathrm{O} 2}=1$. Experimentally, Liu and Ronney ${ }^{29}$ found behavior suggesting a single isolated flame tube in $\mathrm{H}_{2}-\mathrm{N}_{2}$ vs. $\mathrm{O}_{2}-\mathrm{N}_{2}$ flames ( $\mathrm{Le}_{\mathrm{fu}}-$ 0.30, Le $_{\text {ox }}-1.0$ ) very near extinction, but Shay and Ronney ${ }^{33}$ did not find any such behavior in $\mathrm{CH}_{4}-\mathrm{CO}_{2}$ vs. $\mathrm{O}_{2}-\mathrm{CO}_{2}\left(\mathrm{Le}_{\mathrm{fu}}-0.72, \mathrm{Le}_{\mathrm{ox}}{ }^{-}\right.$0.87). Indeed, Chen et al. ${ }^{8}$ found that $\mathrm{CH}_{4}-\mathrm{CO}_{2}$ vs. $\mathrm{O}_{2}-\mathrm{CO}_{2}$ mixtures were only marginally capable of producing cellular structures in nonpremixed flames near extinction, even though in premixtures they readily produce cells for sufficiently high Da. ${ }^{29}$ This again indicates the need for sufficiently low Le in order to observe the unusual sequence of flame-tube behavior predicted computationally.

\section{$\underline{\text { Objectives }}$}

Based on this discussion, the goal of the current work is to determine the effect of flame stretch and thus $\mathrm{Da}$ on the diffusive-thermal instability of flames in low Lewis number mixtures. In particular, we wish to determine if the progression of behavior from continuous flames to chains of tubes to isolated tubes

\footnotetext{
**** For nonpremixed flames with unequal Lewis numbers of fuel and oxygen, the effective Lewis number of the nonpremixed flame (for the purpose of determining the nature of DTI in the flame) is the ratio of the mixture thermal diffusivity to the mass diffusivity of the more completely consumed reactant. This in turn can be determined from Linans criterion $^{30}$ that (for the special case of equal temperatures of the fuel and oxidant streams) when the ratio of the oxidizer mass fraction in the oxidizer stream to fuel mass fraction in the fuel stream is greater/less than the stoichiometric oxidizer-to-fuel mass ratio, the fuel/oxidizer is more completely consumed.
}

as predicted theoretically ${ }^{12,14,15,16}$ as Da is decreased (via reducing the mixture strength, thus decreasing $\mathrm{T}_{\mathrm{ad}}$ and increasing $\beta$, and/or via increasing the strain rate) can be observed experimentally. Since both premixed and nonpremixed flames are of interest, an apparatus is needed that is appropriate for studying for both types of flames. Furthermore, since heat losses are known affect these instabilities, assessment of the effects of conductive losses to the jet exits is needed. Finally, since studies of flame balls have shown the importance of equivalence ratio (i.e. fuel/oxygen ratio, as distinct from fuel concentration in fuel-air mixtures) in flame structures that are enhanced by curvature/Lewis number interactions, an assessment of stoichiometry effects in low-Le stretched premixed flames is also needed.

\section{Apparatus selection}

\section{Approach}

Numerous flow configurations have been used to study stretched flames. Perhaps the most common is the axisymmetric counterflowing jet apparatus. A difficulty with this apparatus in the context of the current study is that extensional strain occurs in both coordinate directions parallel to the flame surface. In contrast, the counterflow slot-jet apparatus provides extensional strain in the direction orthogonal to the plane of the slots, which we shall refer to as the $y$ coordinate direction, but there is no strain in the direction along the length of the slots, which we shall refer to as the $x$ coordinate direction. Thus, the flame is stretched only in one of the two coordinates in the plane of the flame. In this way, a degree of separation can be obtained between the effects of stain on burning intensity and the effects of strain on the flame morphology (e.g. cellular structures). In this sense, the counterflow slot-jet apparatus is somewhat analogous to a flame stabilized around a porous cylinder in a crossflow, i.e. a Tsuji burner ${ }^{7}$ but without the curvature and mean flow effects inherent in that configuration. Another reason for our preference for the slot-jet configuration is that computations ${ }^{34}$ have shown that highly strained regions of turbulent flows exhibit a most probable ratio of strain along the three principal axes in the ratio $0.75: 0.25:-1$, where positive values denote extensional strain. Thus, highly strained regions, where flame stretch effects are most important, do not typically exhibit nearly equal rates of extensional strain along two of the principal axes. The counterflow slot-jet configuration provides strain rates in the ratio 1:0:-1 whereas round jets provide $0.5: 0.5:-$ 1. Thus, the slot-jet configuration provides straining characteristics that are more representative of the conditions of flames in strongly turbulent flows than axisymmetric jets can provide. Hence, the counterflow slot-jet configuration may provide a more realistic assessment of the stretch environment felt by flames in turbulent flows. (It should be noted, however, that the 
laminar flamelet model cannot apply for mixtures with low Le, because even with a uniform mixture in a uniform strain field, the inherent diffusive-thermal instabilities will result in a non-uniform flame front.)

Numerous apparatuses have been used to study low-Le DTI. For premixed flames, many apparatuses are possible since it is not necessary to examine nearextinction conditions. Consequently, freelypropagating flames in tubes 4 and spherically expanding flames $^{5}$ as well as burner-stabilized flames ${ }^{1,2,6}$ have been employed, but these are not conveniently applied to nonpremixed flames. For nonpremixed flames, Garside and Jackson $^{35}$ employed a simple round fuel-jet apparatus, Dongworth and Melvin ${ }^{36}$ used a splitter-plate configuration, Ishizuka and Tsuji ${ }^{7}$ used the cylinder-incrossflow apparatus mentioned above, and Chen et al. ${ }^{8}$ employed a Wolfhard-Parker burner (a rectangular jet of fuel with a co-flowing stream of oxidizer on both sides). In all of these except the cylinder-in-crossflow, the cells are evolving in the direction of flow. The counterflow slot-jet or cylinder-in-crossflow configurations avoid this complication but as mentioned earlier the latter is subject to curvature and mean flow effects, as well as heat loss to the cylinder.

Based on the discussion in the previous two paragraphs, we consider the counterflow slot-jet apparatus to be the most appropriate for this study, in which the objective is to examine the effects of stretch on diffusive-thermal instability in a controlled, systematic way. Moreover, the counterflow slot-jet apparatus essentially duplicates the configuration employed in many of the aforementioned computational studies. ${ }^{12,14,15,16}$

Three different variations of the counterflow slot-jet are employed in this work. For premixed flames, two configurations were employed: premixed combustible gas vs. inert gas, where a single flame is produced, and premixed gas vs. premixed gas, where twin flames are produced on either side of the stagnation plane. The former may be more relevant to turbulent flames since one side of the flame front has fresh reactants whereas the other side has burned products, however, the twinflame configuration is considered here also because it is frequently employed in studies of strained laminar flames and may be relevant to highly strongly wrinkled flames at high turbulence levels where back-to-back flames may exist. It has also been suggested that single premixed-flame studies are relevant to laminar flame quenching, e.g., of rising flames in tubes. ${ }^{37} \mathrm{~A}$ third premixed-flame configuration, namely a single jet impinging on a solid wall, is also possible but was not employed in this study. For non-premixed edgeflames, only one counterflow configuration is possible, namely a fuel + inert mixture vs. an oxygen + inert mixture, which exhibits a single flame at the location where the reactant fluxes are in stoichiometric proportion.

\section{Mixture selection}

$\mathrm{H}_{2}-\mathrm{O}_{2}-\mathrm{N}_{2}$ mixtures were employed in this study in order to obtain sufficiently low Lewis numbers to observe the entire range of low-Le instabilities predicted by theory for both premixed and nonpremixed flames. As noted above, mixtures with reactant Lewis numbers closer to but still less than unity, e.g. lean $\mathrm{CH}_{4}$-air, lean $\mathrm{CH}_{4}-\mathrm{O}_{2}-\mathrm{CO}_{2}$ or rich $\mathrm{C}_{3} \mathrm{H}_{8}$-air mixtures, are found to exhibit cellular structures for premixed (though not nonpremixed) flames yet have not shown any evidence of exhibiting tube-like structures. For premixed flames, $\mathrm{H}_{2}$-air and $\mathrm{H}_{2}$-air- $\mathrm{N}_{2}$ mixtures were used. For single premixed flames, both $\mathrm{N}_{2}$ and air were used for the nonreactive stream, but in no case was a difference between the two found. For nonpremixed flames $\mathrm{H}_{2}$ diluted with $\mathrm{N}_{2}$ was used as the fuel and air was used as the oxidant. The temperature-averaged Lewis numbers of $\mathrm{H}_{2}$ and $\mathrm{O}_{2}$ are approximately 0.29 and 1.02, respectively, resulting in $\phi_{\mathrm{c}}{ }^{-} 0.28$.

\section{Experimental apparatus}

The experimental apparatus we employed (Figure 1) is similar to that used in our previous experimental works on edge flames. ${ }^{29,33}$ The apparatus consisted of two $76 \mathrm{~mm} \times 10 \mathrm{~mm}$ rectangular nozzles configured as a counterflow burner. Steel wool and honeycomb inside the nozzles ensured uniform exit flow. The honeycomb, with a channel width of $0.4 \mathrm{~mm}$ and a length of $13 \mathrm{~mm}$, was mounted flush with the jet exits. This uniformity was verified by examining stable highLe planar premixed flames, which were found to be parallel to the jet exits to within $-3 \%$ of the separation distance. Since the ideal y velocity profile is linear, and because the premixed flame will adjust its location to the $y$ value where the burning velocity and flow velocity are equal, this indicates that the y velocity profile is uniform to within $-3 \%$. The nozzles (and thus reactants) were maintained at room temperature by water cooling. The lower nozzle was mounted on a translation stage with a micrometer for adjusting the nozzle separation between the slot exits. (Unlike our previous studies on edge flames, for this work the two jet exits were always maintained parallel to each other). Except where noted, a constant nozzle spacing (d) of $12.7 \mathrm{~mm}$ was employed. Steel mesh screens were placed above and below the test section of the apparatus to minimize disturbances due to laboratory drafts. As shown in Figure 1, this apparatus was placed inside a steel box to further isolate the flames from drafts and facilitate ventilation.

Commercial mass flow controllers with accuracy of $-1 \%$ of full scale (verified by calibration with wet-test meters) delivered the combustible gases to the nozzles. The mass-flow controllers were commanded by a PCbased digital-to-analog converter board and custom software that enabled independent control of gas 
composition and exit velocity (V) for each nozzle. The flow velocities at the nozzle exits were calculated by dividing the gas volume flow rate by the nozzle exit area.

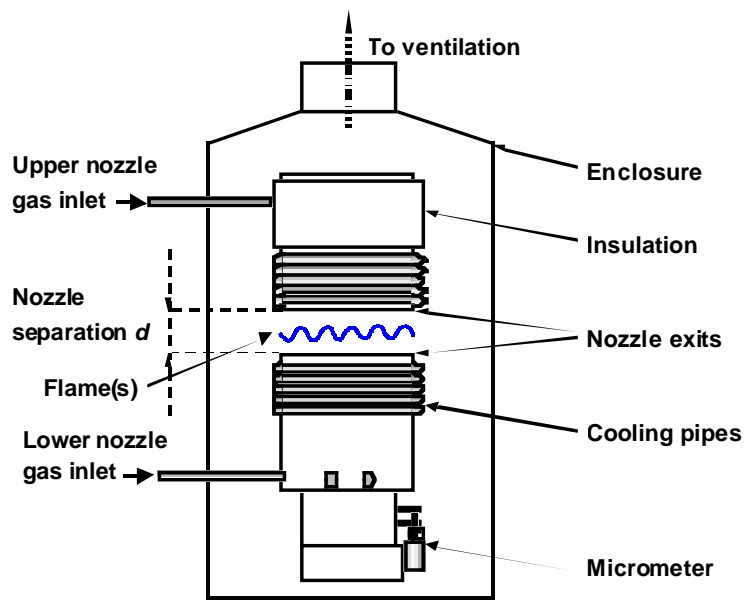

Figure 1. Schematic diagram of counterflow slot-jet burner.

While the large aspect ratio (7.6) of the slot jets ensures that the convective velocities in the direction of the long dimension of the slot jet (i.e. in the $\mathrm{x}-$ direction) is much weaker than in the shorter dimension (the y-direction), it is nevertheless not zero. Consequently, it was found that some flame structures, especially isolated flame tubes, tended to be swept slowly from the center of the slot (in the $\mathrm{x}$ direction) towards one or both edges. While our previous work $^{29,33}$ showed that this lateral flow had no detectable effect on edge flame properties or the threshold conditions for diffusive-thermal instabilities, it minimizes the time for which isolated tubes and other structures can be observed. Consequently, to eliminate this flow, for most tests end walls were placed at both edges of the slots. These walls were of the same height as the nozzle spacing (d) and $50 \mathrm{~mm}$ long in the $\mathrm{y}$ direction (the direction of extensional strain). This enabled flame tubes and similar structures to be observed for indefinite periods of time. Further discussion of wall effects are given in section 4.1.3.

As discussed in our previous works, ${ }^{29,33}$ the global strain rate in the counterflow configuration is given by, assuming equal velocities of upper and lower streams ${ }^{38}$

$$
\sigma=\frac{V_{\text {upper }}+V_{\text {lower }}}{d}
$$

where $\sigma$ is the strain rate, $V_{\text {upper }}$ and $V_{\text {lower }}$ are the upper and lower jet exit velocities. The local $\sigma$ will vary in the streamwise direction due to thermal expansion effects, and moreover for the nonuniform flames of most interest in this study $\sigma$ will vary in the $\mathrm{x}$ direction as well. Thus, does not appear that any meaningful local $\sigma$ at the flame could be defined, especially considering how difficult it has been to determine a proper definition of $\sigma$ for a conventional one-dimensional counterflow flame and how to extrapolate these data to zero strain rate to determine the unstretched laminar burning velocity. ${ }^{39}$ Also, correlations of strain effects for turbulent flames ${ }^{40}$ employ global strain rate estimates based on the coldgas conditions. Furthermore, most early experiments on strained flames, e.g., Ishizuka and Tsuji, reported only global strain rates, and most theoretical works on edge-flames and instabilities of stretched flames ${ }^{12,14,15,16}$ have used the constant-density assumption, thereby sidestepping the issue of flow-field modification near the flame edge due to thermal expansion.

Because the $\mathrm{H}_{2}-\mathrm{O}_{2}-\mathrm{N}_{2}$ flames of interest in this study do not produce significant visible emission, a He-Ne laser shadowgraph imaging system was used. One benefit of a shadowgraph system for the current study is that it is sensitive to the second spatial derivative of the index of refraction. Since for a gas the index of fraction is proportional to density, which in turn is inversely proportional to temperature for the nearly constant pressure flames examined here, the shadowgraph provides a qualitative image of the regions of large second spatial derivative of temperature. Since the effect of heat release in a steady one-dimensional flame is a change in the second spatial derivative of temperature, ${ }^{26}$ the shadowgraph technique provides a means to visualize regions of high heat release rate (albeit a path-integrated visualization). The images recorded by flames were recorded by a video camera (framing rate $30 \mathrm{~Hz}$, shutter speed 1/60 sec). This framing rate and shutter speed was found to be sufficient for the relatively slow evolution time scales of the flame structures found in this study. The images were then digitized and enhanced by a video processing system.

\section{Procedures}

Finding transitions between modes was accomplished in one of two ways. One way was by fixing the strain rate, and increasing or decreasing the fuel concentration (with equal compositions in each stream for twin premixed flames) until a transition was noted. The second was by fixing the fuel concentration, and increasing or decreasing $\sigma$ by increasing or decreasing the jet exit velocities. Except where noted, $\mathrm{V}_{\text {upper }}$ and $\mathrm{V}_{\text {lower }}$ were kept equal. Each transition was repeated at least three times and the average the fuel concentration or $\sigma$ at transition is reported below. No significant hysteresis was observed in the transitions, with the exceptions noted below.

\section{$\underline{\text { Results }}$}

\section{$\underline{\text { Twin premixed flames }}$}

Figure 2 shows the various modes of flame structures observed in twin premixed $\mathrm{H}_{2}$-air flames, and Figure 3 shows sample images of these flames. For a fixed fuel concentration, two types of extinction limits 
are observed, one at sufficiently high $\sigma$ and the other at sufficiently low $\sigma$. This is probably due to a transition from a strain-induced extinction mechanism at high $\sigma$ to a heat-loss extinction mechanism at low $\sigma$. This dual-limit extinction behavior of counterflow premixed flames has been demonstrated previously both theoretically $^{41,42}$ and experimentally ${ }^{43}$ for counterflow flames subject to radiative heat loss. In the experiments, ${ }^{43}$ microgravity conditions were needed to avoid buoyancy effects and enable the radiative extinction limit to be observed. ${ }^{44}$ In the current experiments the heat loss is probably conductive loss to the burner rims rather than radiative loss, since it was found that the lower limit was sensitive to $d$ (see results section for nonpremixed flames.) While we are unaware of any theoretical studies of counterflow flames with conductive heat loss, it is well known ${ }^{45}$ that premixed flames stabilized on a porous-plug burner are subject to extinction due to conductive loss at low exit velocities (corresponding to low $\sigma$ in the current study). The current water-cooled honeycomb-type nozzles would cause conductive losses in a similar way, since for both types of apparatus at low exit velocities (less than $S_{L}$ ) the flame will be attached to the plug or nozzle but cannot propagate through it because the pore or honeycomb dimension is far smaller than the mixture quenching distance. Consequently, we have every reason to believe that the dual-limit behavior is due to stretch-induced extinction at high $\sigma$, and conductive loss extinction at low $\sigma$. The dual-limit behavior is also known theoretically and experimentally for nonpremixed counterflow flames with radiative loss, ${ }^{46}$ though again we are unaware of an analysis of duallimit behavior specifically for conductive loss to the nozzles.

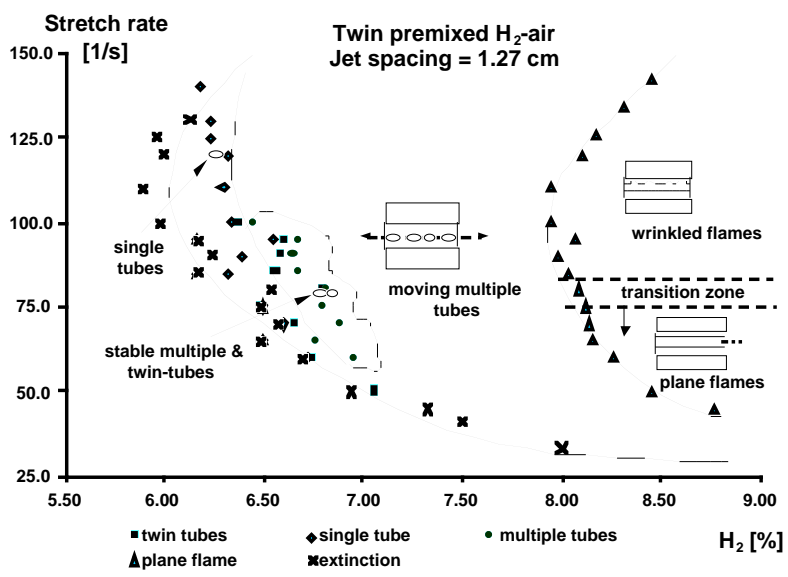

Figure 2. Stability and extinction limits for twin $\mathrm{H}_{2}$-air premixed flames.

As predicted computationally, ${ }^{12}$ several different types of instabilities are observed as Da is decreased, either by reducing fuel concentration or increasing $\sigma$. For example, note the progression of instability behavior seen in Figure 2 for $\sigma=75 \mathrm{~s}^{-1}$ as the fuel concentration is reduced. For sufficiently rich mixtures, two nearly planar flames are observed (Figure 3a) or moderately wrinkled observed. The orthogonal view shown in Figure $3 \mathrm{~b}$ confirms that this is a nearly planar structure. For weaker mixtures, twin moderately wrinkled flames are seen (Figure 3c). For still weaker mixtures a transition first to an array of tubes moving outward from the center (in the x-direction) of the jets toward the outer edges of the jets is seen (Figure $3 \mathrm{~d}$ ). Figure $3 \mathrm{e}$ confirms that these structures are tube-like rather than (for example) ball-like or disc-like. A schematic illustration of the transition from wrinkled twin flames to flame tubes is shown in Figure 4. For still weaker mixtures, stationary twin tubes (Figure 3f) then stationary single tubes (Figure $3 g, h$ ), then to extinction. This is mostly consistent with the predictions of Buckmaster and Short, ${ }^{12}$ though these authors pointed out that their results depended somewhat on the initial conditions, and that they had not conducted a complete parametric study. In fact, their computations showed that twin tubes could exist at lower Da than single tubes.

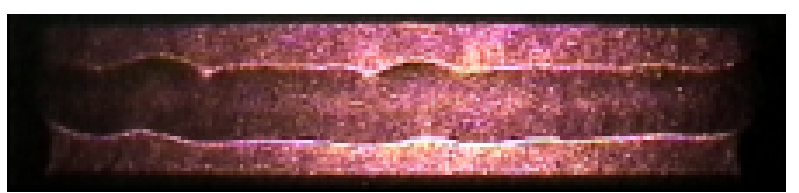

Figure 3. Shadowgraph images of twin premixed flames. Except where noted, jet spacing is $1.27 \mathrm{~cm}$. (a). Plane flames, $8.26 \% \mathrm{H}_{2}$, strain rate $60 \mathrm{~s}^{-1}$.

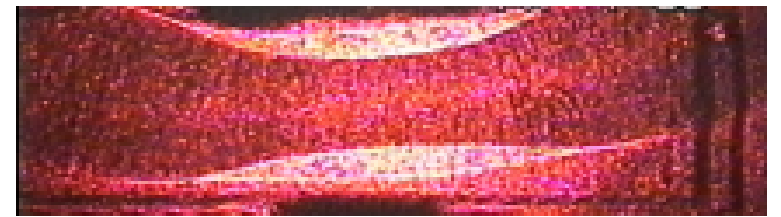

Figure 3(b) Orthogonal view, jet spacing $1.35 \mathrm{~cm}$, $8.26 \% \mathrm{H}_{2}$, strain rate $56 \mathrm{~s}^{-1}$.

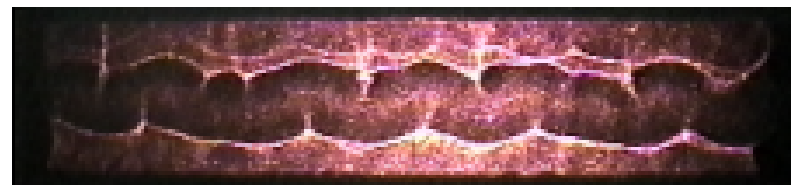

Figure 3(c) Wrinkled flames, $\mathrm{H}_{2}=8.10 \%$, stretch rate $110 \mathrm{~s}^{-1}$.

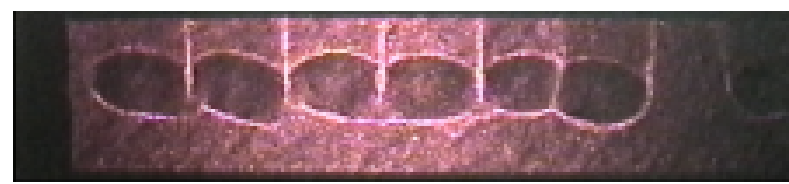

Figure 3(d) Moving tubes front view, $6.96 \% \mathrm{H}_{2}$, strain rate $60 \mathrm{~s}^{-1}$.

Figure $3 g$ and $h$ show that stationary single tubes exist near the center of the jets for low $\sigma$ and near the end of the jets (where the side walls are present) for high $\sigma$. This is likely because the walls induce viscous losses that reduce $\sigma$ in this vicinity. This lower $\sigma$ is beneficial to flame survival for conditions on the upper 
(high- $\sigma$ ) extinction branch seen in Figure 2, since lower $\sigma$ will result in less tendency to extinguish. Furthermore, heat loss is not dominant on this branch, so the additional heat loss to the wall does not induce extinction. Thus, for conditions corresponding to the upper extinction branch, flame tubes near the side walls can survive slightly higher global $\sigma$ than flame tubes near the center of the jet. In contrast, on the lower branch, the lower $\sigma$ and increased heat loss present near the side walls are detrimental to flame survivability, thus flame tubes near the center of the jet can survive slightly higher global $\sigma$ than flame tubes near the side walls. This discussion provides further evidence that the dual-limit behavior seen in Figure 2 is due to stretch extinction at high $\sigma$ and heat loss extinction at low $\sigma$. It should be noted that the walls act to induce a slight strain rate gradient that helps to stabilize flames, in a manner somewhat similar to that used in prior edge-flame studies. ${ }^{29,33}$

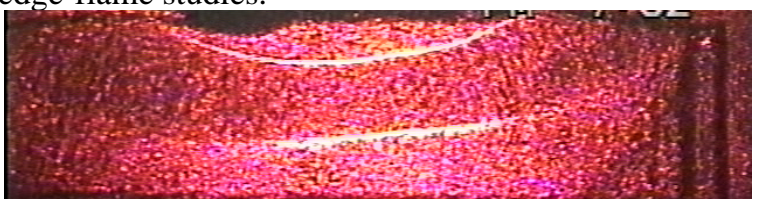

Figure 3(e) Moving tubes side view, jet spacing 1.35 $\mathrm{cm}, 6.96 \% \mathrm{H}_{2}$, strain rate $56 \mathrm{~s}^{-1}$.

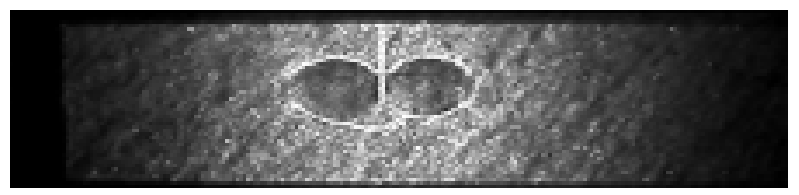

Figure 3(f). Twin tubes, $6.68 \% \mathrm{H}_{2}$, strain rate $60 \mathrm{~s}^{-1}$.

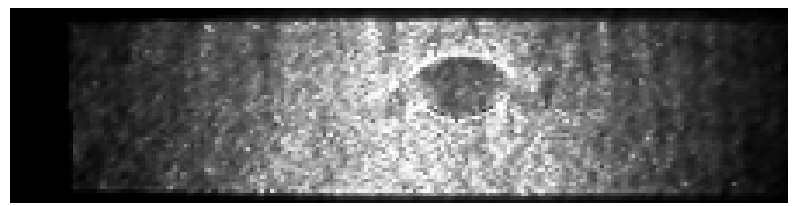

Figure $3(\mathrm{~g})$ Single tube in center, $6.64 \% \mathrm{H}_{2}$, strain rate $60 \mathrm{~s}^{-1}$.

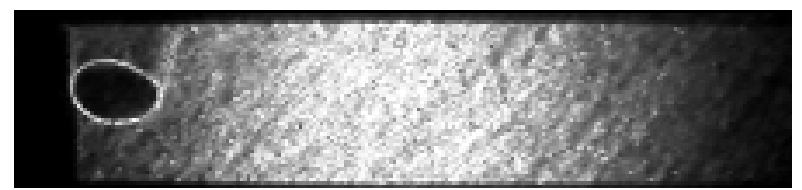

Figure 3(h) Single tube near wall, $6.11 \% \mathrm{H}_{2}$, strain rate $100 \mathrm{~s}^{-1}$.

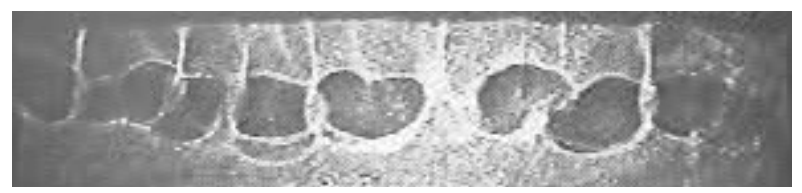

Figure 3(i). Turbulent flame structure, $6.9 \% \quad \mathrm{H}_{2}$, strain rate $158 \mathrm{~s}^{-1}$.

The side view of the flame tubes (Figure 3e) shows that moving tubes curl upward due to buoyancy, but since the tube radius is much smaller than the radius of curvature of tube due, the tube structure is not expected to be affected by buoyancy.

For the single tubes, the cross-section of the tubes is not round but is generally somewhat longer dimension in the unstrained $\mathrm{x}$-direction than in the compressionally strained $y$-direction (the vertical direction in these figures). This is consistent with theoretical predictions of flame tubes. ${ }^{12,16}$

Similar results were observed as $\sigma$ was increased, though for fixed fuel concentration it was not possible to observe as many instability modes as with changing $\sigma$. Part of this is due to the apparent transition to turbulent flow at high $\sigma$ (see below). Moreover, since the aforementioned computational studies did not consider heat losses to the jet exits, no corresponding change in instability mode for decreasing $\sigma$ was predicted. It is interesting to note that the experimentally-observed instability behavior is somewhat symmetric with respect to the high and low $\sigma$ limits. While there is no rigorous analogy between the behavior near the two limits, the experiments suggest that the observed instability behavior is similar regardless of whether finite residence time or heat loss causes near-extinction conditions to exist. It is well known that for unstretched flames, both volumetric heat losses $^{19}$ and heat losses to a porous plug ${ }^{45, \text { Error! Bookmark }}$ not defined. increase the tendency for flame instability, thus such behavior can be expected.

At $\sigma>140 \mathrm{~s}^{-1}$, a sudden transition to marked unsteadiness of the flame structure was observed (Figure 3i), regardless of the type of flame existing at $\sigma$ $<140 \mathrm{~s}^{-1}$. We interpret this to be a transition to a turbulent flow. It was found the jet velocity $(\mathrm{V})$ at this transition (recall that $\mathrm{V}_{\text {upper }}=\mathrm{V}_{\text {lower }}$ for all twin premixed cases tested) was practically independent of the jet spacing $d$. Consequently, we believe that the appropriate Reynolds number ( $R e)$ is probably that based on the jet width (w) rather than the spacing (d), though we have not yet tested the effect of w. In this case $\operatorname{Re} \equiv \mathrm{Vw}_{\mathrm{w}} / \mathrm{v}_{\mathrm{o}}=\sigma \mathrm{dw} / 2 \mathrm{v}_{\mathrm{o}}$ where $\mathrm{v}_{\mathrm{o}}$ is the kinematic viscosity at ambient temperature, is 600 - 30 at this transition. Experiments were also conducted using helium vs. air, which has a density and viscosity ratio similar to that of combustion products vs. cold reactants, and almost the same transition Re was found. Egolfopoulos $^{47}$ noted a similar limitation of round-jet counterflow flames, at similar values of Reynolds number. Consequently, we conclude that the instability at high $\mathrm{V}$ or $\sigma$ purely hydrodynamic, and not a flame-generated instability due to thermal expansion or Lewis number effects. (This does not imply that hydrodynamics are unimportant at lower $\sigma$ or Re, merely that hydrodynamic instability is dominant at higher $\sigma$ or Re.)

This transition to turbulence limits our ability to study a large portion of the upper (stretch-induced) branch of the extinction curve. The aforementioned theoretical works all assumed constant density and 
moreover did not solve the Navier-Stokes hydrodynamics equations, instead assuming a simple plane strain, and thus cannot predict a transition to turbulence.

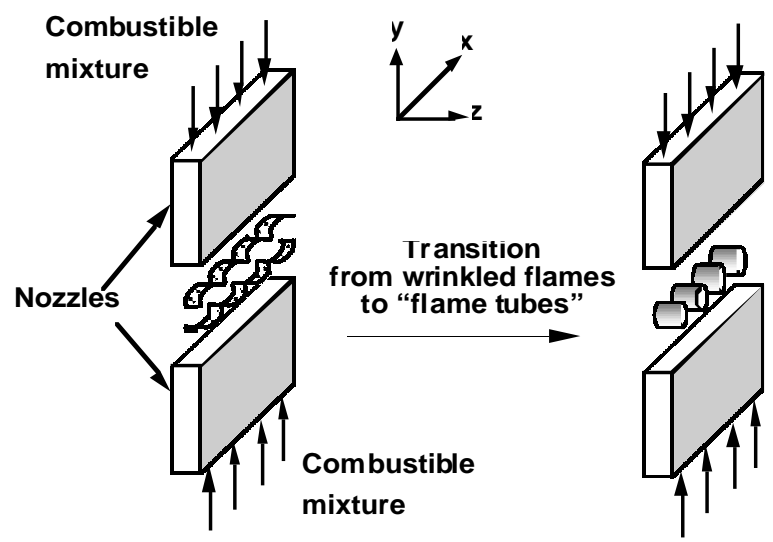

Figure 4. Schematic illustration of transition from wrinkled flames to "flame tubes."

Figure 5 shows the effect of equivalence ratio $(\phi)$ on the instability behavior. Most premixed flame studies have employed fuel-air mixtures, thus changing $\phi$ changes not only the fuel to oxygen ratio relative to stoichiometric, but also changes the adiabatic flame temperature of the mixture. In order to examine the effect of $\phi$ without changing the adiabatic flame temperature, mixtures having a fixed fuel concentration but varying $\mathrm{O}_{2}: \mathrm{N}_{2}$ ratios were tested. Since $\mathrm{O}_{2}$ and $\mathrm{N}_{2}$ have practically identical mole-based values of specific heat, these mixtures have practically identical adiabatic flame temperatures. Moreover, the thermal diffusivity of $\mathrm{O}_{2}$ and $\mathrm{N}_{2}$ are practically identical. The value of this approach is that every point on Figure 5 has practically the same adiabatic flame temperature and heat and mass diffusion coefficients, and thus nearly the same planar steady adiabatic burning velocity. Consequently, observed differences in behavior at different $\phi$ are due solely to differences in transport processes.

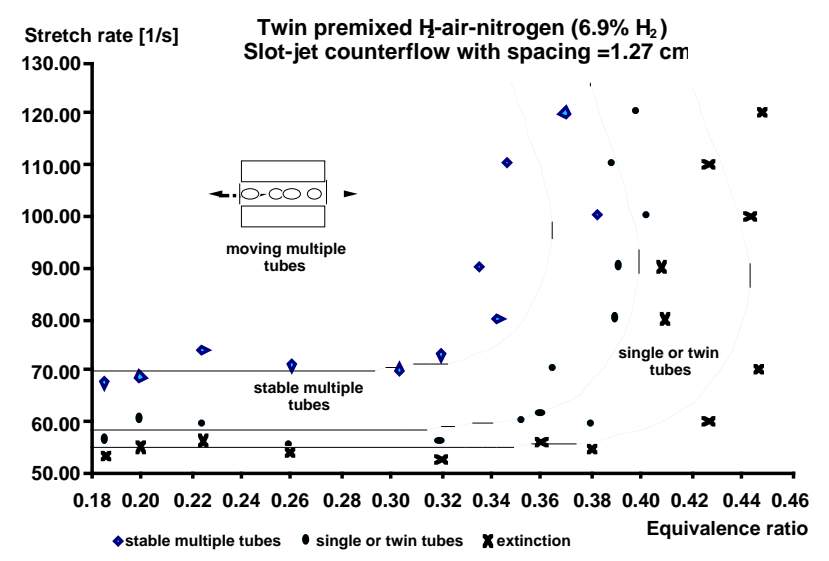

Figure 5. Stability and extinction limits for twin $\mathrm{H}_{2}$-air premixed flames in $6.9 \% \quad \mathrm{H}_{2}$ mixtures with varying $\mathrm{O}_{2}: \mathrm{N}_{2}$ ratios.
A fuel concentration of $6.9 \% \quad \mathrm{H}_{2}$ was chosen because, as Figure 2 shows, this mixture can exhibit a wide variety of phenomena depending on $\sigma$. Figure 5 shows that $\phi$ has practically no effect on the instabilities for $\phi<0.32$, whereas in the range $0.32<$ $\phi<0.44$, a rapid change is observed. For $\phi>0.44$, no flames of any kind could be observed. It is interesting to note that these values of $\phi$ are close to the critical equivalence ratio $\phi_{c}$ for the transition from lean to rich burning at the surface of flame balls (see Introduction). It should be noted that except for the data shown in Figure 5, all twin premixed flames tested in this work have values of $\phi$ that are well below $\phi_{\mathrm{c}}$ and thus can be considered to have an effective Le equal to $\mathrm{Le}_{\mathrm{H} 2}$.

\section{$\underline{\text { Single premixed flames }}$}

Of the three flame configurations tested, the single premixed flame configuration showed the most varied range of instability modes. Figure $6 a$ and $b$ show a trend somewhat similar to that for twin premixed flames in that a transition from some type of wrinkled flame structure to tube-like structures is found as the fuel concentration is reduced, but there is considerable hysteresis in this process. In particular, the transition to tubular flames is found only when starting with a high fuel concentration and decreasing the concentration, and not when starting with a low fuel concentration and increasing the concentration. Furthermore, single flat flames are observed at low fuel concentrations, completely unlike the situation with twin premixed flames. The reasons for these differences will be apparent based on the observed flame structures (Figure 7).

For single premixed flames, the weakest mixtures that could be burned are about $7 \% \mathrm{H}_{2}$ as opposed to $6 \%$ $\mathrm{H}_{2}$ for twin premixed flames. This difference is expected because of the greater downstream heat loss experienced by a single premixed flame impinging on a cold nonreacting stream as compared to back-to-back premixed flames.

As with twin premixed flames, a transition to turbulence is found for single premixed flames, but at $\sigma$ - $125 \mathrm{~s}^{-1}$, which is about $10 \%$ lower than for twin premixed. Probably this difference occurs because there a smaller region of hot combustion products for the single premixed case, and thus a lower effective $v$. If the Reynolds number at the transition to turbulence is the same for both cases, the single premixed flame would then have a lower $\mathrm{V}$ and thus lower $\sigma$ at the transition. Because of the transition to turbulence, the upper stretch-induced extinction branch could not be observed for single premixed flames.

Figure 7 shows shadowgraph images of single premixed flame structures. For very high fuel concentrations or low exit velocities, the flames are attached to the jet exits (Figure 7a, b). Because of the 
low Le, the flames do not attach uniformly but rather exhibit cellular structures. The orthogonal view (Figure 7c) shows that for single premixed flames, unlike the twin premixed case (Figure $3 b$ ), the flames attach to the jet exits. Both views clearly show not only the flame itself, but also the mixing layer between the hot combustion products and the cold inert stream (the lower bright region in these images.)

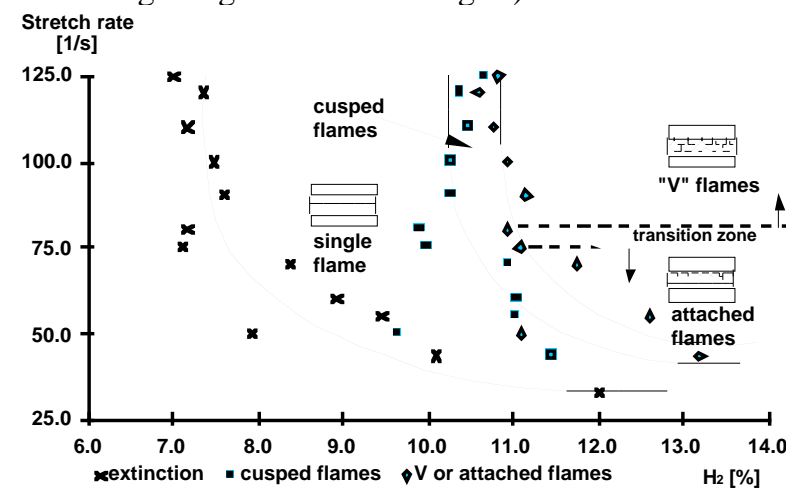

Figure 6. Stability and extinction limits for single $\mathrm{H}_{2}$ air premixed flames. (a) decreasing fuel concentration

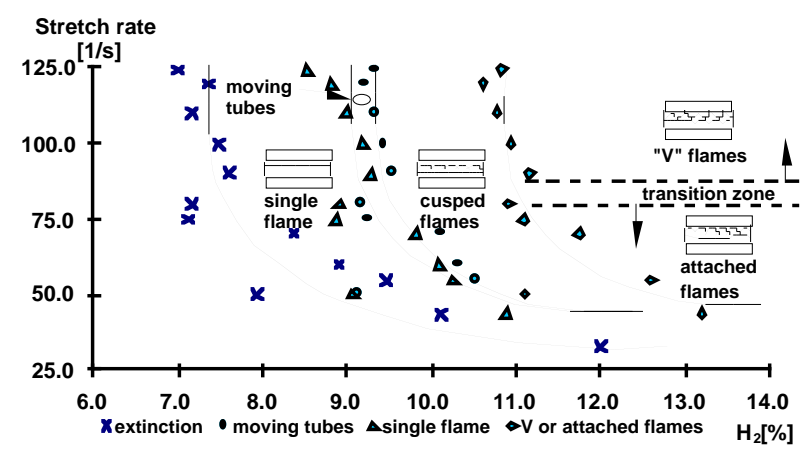

Figure 6. Stability and extinction limits for single $\mathrm{H}_{2}$ air premixed flames. (b) increasing fuel concentration

For slightly weaker mixtures or higher flow velocities (Figure 7d) the flame lifts off partially, resulting in a series of "V-flames." For still weaker mixtures or higher flow velocities (Figure 7e, f, g), the flames detach fully and form cusped flames reminiscent of half of a flame tube. The orthogonal view (Figure 7f) shows that for these flames also, the flames are attached to the jet exit. For yet weaker mixtures (Figure 7h) or higher flow velocities, the cusp-like flames close up to form moving tubes very similar to those found in twin premixed flames (Figure $3 \mathrm{~d}$ ) even though for single premixed flames, reactive mixture issues from only one jet.

For the weakest mixtures, remarkably a single flat premixed flame reappears, first in conjunction with moving tubes (Figure 7i) and finally by itself (Figure $7 \mathrm{j}$ ). The orthogonal view (Figure 7k) shows that this flat flame is attached to the jet exit and probably follows the shear layer between the reactive stream and the quiescent ambient air. Note that the lower mixing layer between hot combustion products and the cold inert stream all but disappears for these cases. It is surprising that the most robust flame observed in single premixed flames is flat rather than curved. In some cases flames were attached to both sides of the jet exits, and in other cases, such as that shown in Figure $7 \mathrm{k}$, the flame extinguished on one side. Presumably for the nonpremixed flame this structure could not exist without the shear layer between the jet and the ambient air surrounding the burner; future experiments with an inert $\mathrm{N}_{2}$ co-flow will test this proposition. Also surprisingly, single tube flames were not observed in single premixed flame cases, except occasionally as a transient before extinction (Figure 71).

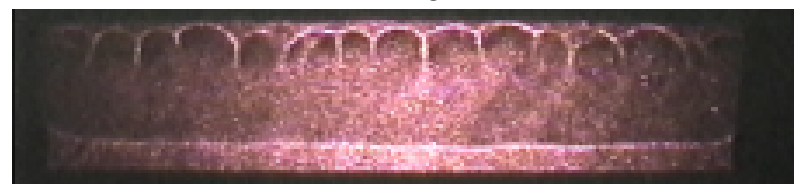

Figure 7. Shadowgraph images of single premixed flames. Reactive mixture flows from upper jet; inert mixture flows from lower jet; jet spacing $1.27 \mathrm{~cm}$. (a). Attached flames, $13.20 \% \mathrm{H}_{2}$, strain rate $44 \mathrm{~s}^{-1}$. V $V_{\text {upper }}$ $=35.0 \mathrm{~cm} / \mathrm{s} \quad V_{\text {lower }}=20.4 \mathrm{~cm} / \mathrm{s}$. (Upper wrinkled bright zone is flame front; lower bright zone is mixing layer between burned gas and cold inert stream.)

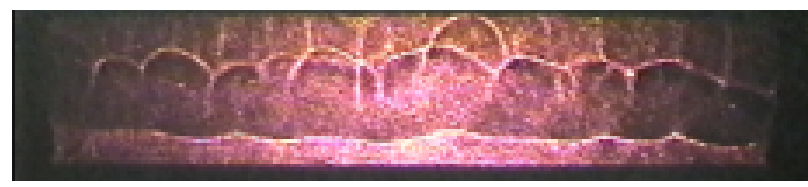

Figure 7 (b) Attached flames, $11.1 \% \mathrm{H}_{2}$, strain rate 75 $\mathrm{s}^{-1}, V_{\text {upper }}=60.2 \mathrm{~cm} / \mathrm{s} \quad V_{\text {lower }}=35.1 \mathrm{~cm} / \mathrm{s}$

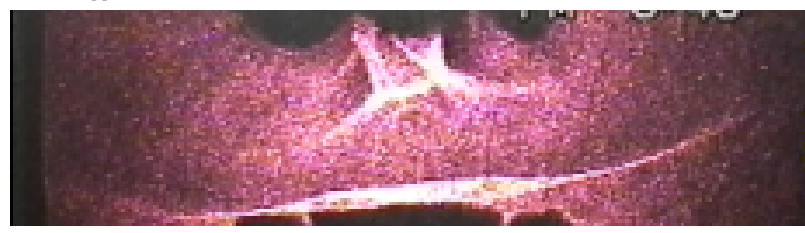

Figure 7 (c) Orthogonal view, Attached flames, $11.9 \%$ $\mathrm{H}_{2}$, strain rate $80 \mathrm{~s}^{-1}$.

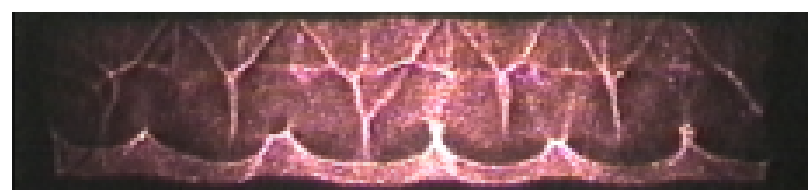

Figure $7(d)$ " $V$ " flames, $11.0 \% \mathrm{H}_{2}$, strain rate $110 \mathrm{~s}^{-1}$. $V$ flames, $V_{\text {upper }}=88.2 \mathrm{~cm} / \mathrm{s} \quad V_{\text {lower }}=51.5 \mathrm{~cm} / \mathrm{s}$

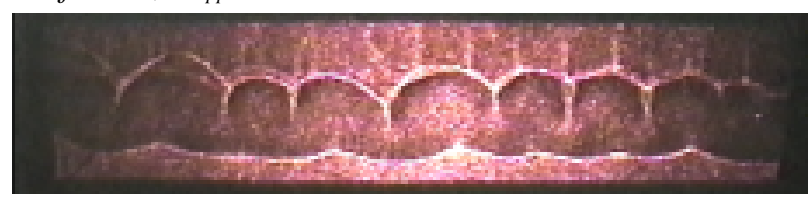

Figure 7 (e) Cusped flames, $10.9 \% \mathrm{H}_{2}$, strain rate 80 $\mathrm{s}^{-1}$. $V_{\text {upper }}=64.2 \mathrm{~cm} / \mathrm{s} \quad V_{\text {lower }}=37.4 \mathrm{~cm} / \mathrm{s}$. 


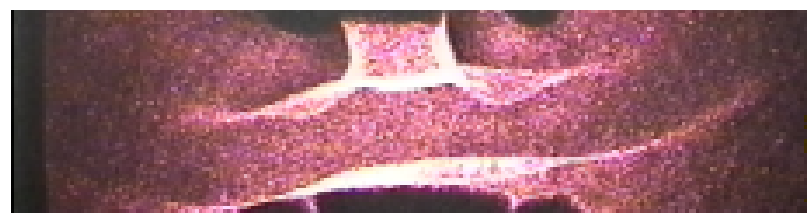

Figure 7 (f) Orthogonal view of cusped flames, $10.7 \%$ $\mathrm{H}_{2}$, strain rate $80 \mathrm{~s}^{-1}$.

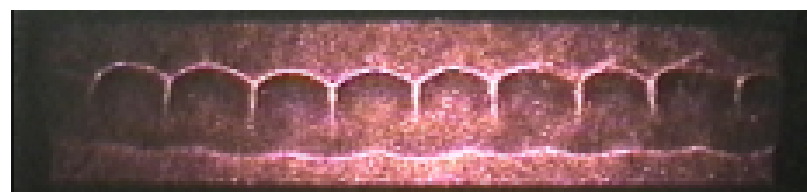

Figure $7 \mathrm{~g}$ ) Cusped flames, $10.3 \% \mathrm{H}_{2}$, strain rate 50 $\mathrm{s}^{-1} . V_{\text {upper }}=40.1 \mathrm{~cm} / \mathrm{s} \quad V_{\text {lower }}=23.4 \mathrm{~cm} / \mathrm{s}$.

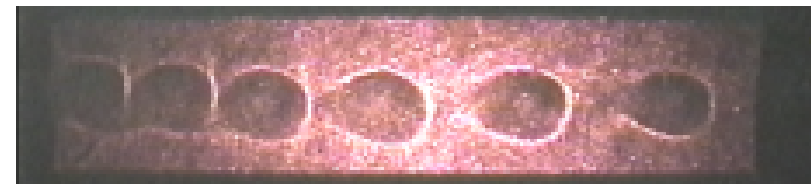

Figure 7 (h) Moving tubes, $9.1 \% \mathrm{H}_{2}$, strain rate $50 \mathrm{~s}^{-1}$. $V_{\text {upper }}=40.1 \mathrm{~cm} / \mathrm{s} \quad V_{\text {lower }}=23.4 \mathrm{~cm} / \mathrm{s}$.

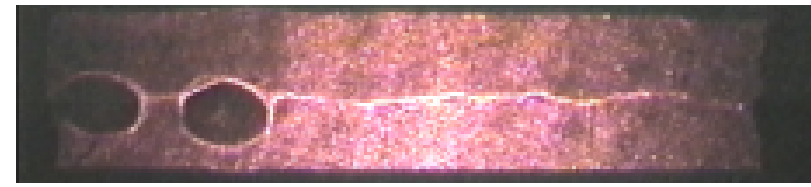

Figure 7 (i) Single flame with moving tubes, 9.0\% $\mathrm{H}_{2}$, strain rate $110 \mathrm{~s}^{-1} . \quad V_{\text {upper }}=40.1 \mathrm{~cm} / \mathrm{s} \quad V_{\text {lower }}=23.4$ $\mathrm{cm} / \mathrm{s}$.

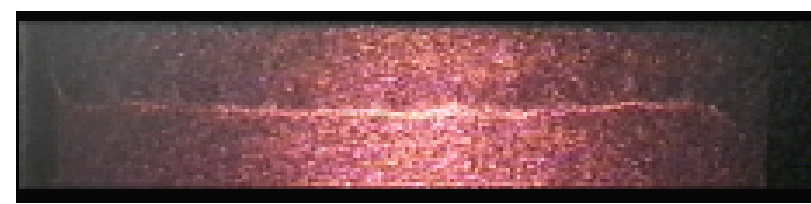

Figure 7 (j) Single flame, $8.9 \% \mathrm{H}_{2}$, strain rate $70 \mathrm{~s}^{-1}$.

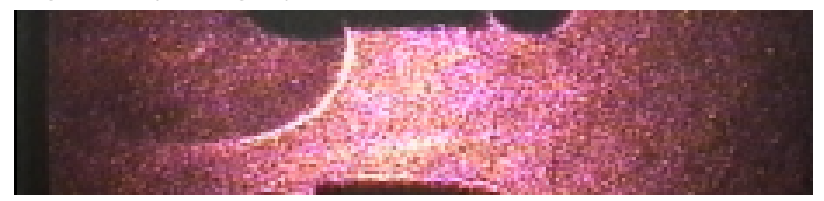

Figure 7 ( $k$ ) Orthogonal view corresponding to single flame, $8.0 \% \mathrm{H}_{2}$, strain rate $80 \mathrm{~s}^{-1}$.

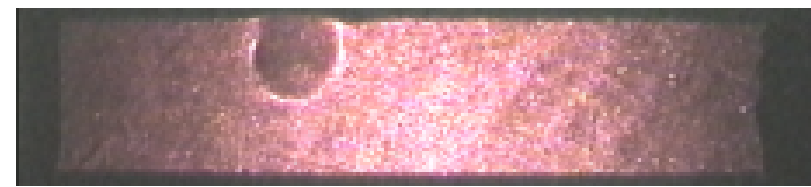

Figure 7 (l) Transient single tube just before extinction, $8.0 \% \mathrm{H}_{2}$, strain rate $110 \mathrm{~s}^{-1}$.

\section{$\underline{\text { Nonpremixed flames }}$}

Figure 8 shows the regimes of behavior observed for nonpremixed flames. For our standard jet spacing $(1.27 \mathrm{~cm})$ (Figure $8 \mathrm{a})$ only plane flames, moving tubes or extinction is normally observed. However, for a few cases another type of flame, namely a flat flame superficially similar to that seen for the single premixed configuration, bifurcates from the premixed flame branch and could burn down to remarkably low fuel concentrations (about $8.8 \% \mathrm{H}_{2}$ in $\mathrm{N}_{2}$ ). When mixed with air in stoichiometric proportions, this corresponds to $7.3 \% \mathrm{H}_{2}$, which is close to the limit observed for single premixed flames with similar structure. For a smaller jet spacing (Figure 8b), which results in a narrower range of flammable conditions because of the greater heat losses, a small range of single or multiple tubes is observed, but the bifurcation to a flat flame was not seen for this gap spacing. By comparing Figure $8 \mathrm{a}$ and $\mathrm{b}$, it is seen that the upper stretchinduced extinction branch is practically unaffected by the gap, but the lower branch is strongly affected and the flammable range is narrower for the smaller gap. This is further evidence that the lower extinction branch is in fact due to heat losses.

As with the premixed flame configurations, a transition to turbulence was found at $\sigma^{-} 125 \mathrm{~s}^{-1}$, which is practically the same as that found for single premixed flames. This similarity to the single premixed flame configuration is reasonable considering that both cases yield only a single flame whereas the twin premixed flame configuration yields two flames and thus a larger high-viscosity burned gas region.

Figure 9 shows shadowgraph images of the observed flame structures. At high Da (Figure 9a, b), corresponding to high fuel concentration or low stretch rate, a flat flame is observed. For weaker mixtures (Figure 9c, d), moving tubes are observed and for still weaker mixtures, isolated single tubes (Figure 9e) or occasionally multiple tubes (Figure 9f) are observed. As with premixed flames, the cross-section of the tubes is not round but is generally somewhat longer dimension in the unstrained direction (the horizontal direction in Figure $9 \mathrm{e}$ and $\mathrm{f}$ ) than in the compressional strain direction (the vertical direction in these figures). It is noteworthy that the premixed tubes (for example Figure $3 \mathrm{~g}, \mathrm{~h})$ and nonpremixed tubes are similar. This is probably because in the nonpremixed case the strain rate is well above the extinction value for the planar flame and thus the reactant streams mix without burning initially, causing the flame to assume a somewhat premixed-like character. The flat-flame mode (Figure $9 \mathrm{~g}, \mathrm{~h}$ ) is similar to that seen for single premixed flames (Figure $7 \mathrm{j}, \mathrm{k}$ ) where the flame front is aligned with the shear layer between the reactive mixture jet (single premixed flame) or fuel jet (nonpremixed flame). Presumably for the nonpremixed flame this structure could not exist without the ambient air surrounding the burner; future experiments with an inert $\mathrm{N}_{2}$ co-flow will test this proposition. 


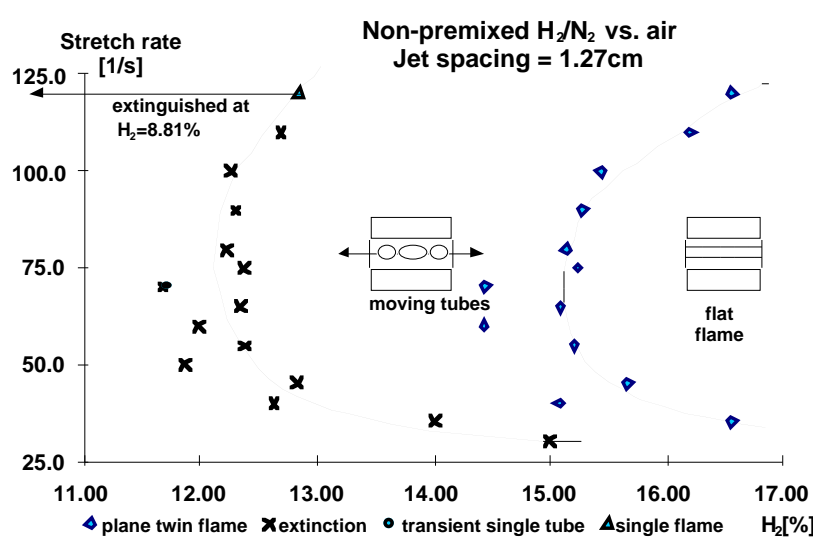

Figure 8. Stability and extinction limits for nonpremixed $\mathrm{H}_{2}$-air premixed flames. (a) jet spacing 1.27 $\mathrm{cm}$.

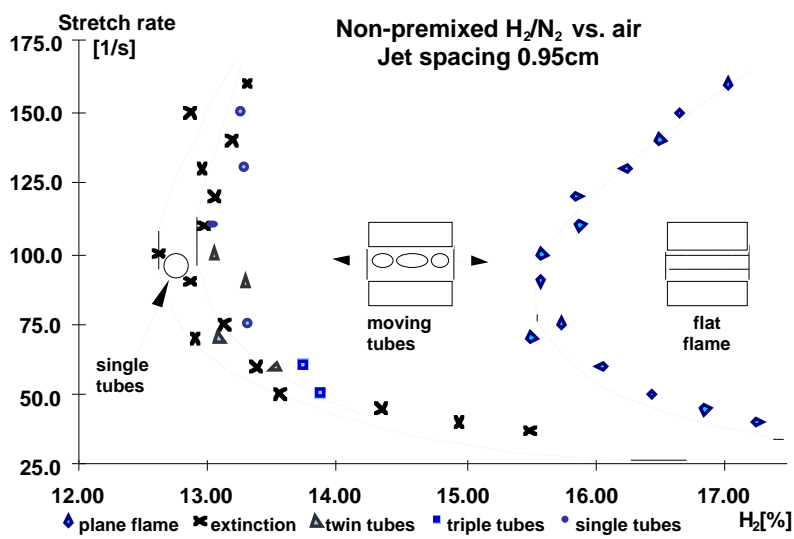

Figure 8. Stability and extinction limits for nonpremixed $\mathrm{H}_{2}$-air premixed flames. (b) jet spacing 0.95 $\mathrm{cm}$.

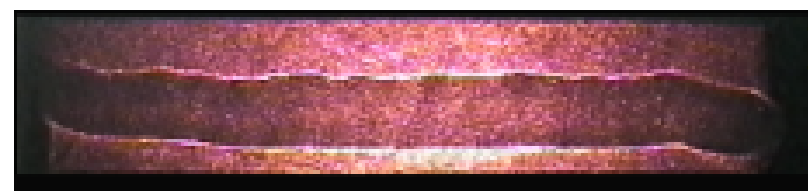

Figure 9. Shadowgraph images of nonpremixed flames. $\mathrm{H}_{2}-\mathrm{N}_{2}$ mixture flows from upper jet; air flows from lower jet; jet spacing $1.27 \mathrm{~cm}$. (a) Plane flames front view, $15.3 \% \mathrm{H}_{2}$, strain rate $75 \mathrm{~s}^{-1}, . V_{\text {upper }}=$ $58.6 \mathrm{~cm} / \mathrm{s} \quad V_{\text {lower }}=36.6 \mathrm{~cm} / \mathrm{s}$. (Upper bright zone is flame front.)

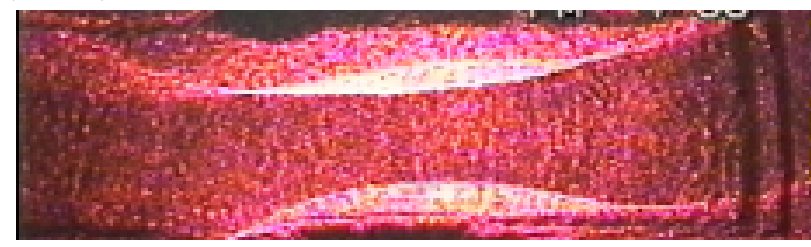

Figure 9(b). Plane flames orthogonal view, $15.3 \% \mathrm{H}_{2}$, strain rate $71 \mathrm{~s}^{-1}, V_{\text {upper }}=58.6 \mathrm{~cm} / \mathrm{s} V_{\text {lower }}=36.6 \mathrm{~cm} / \mathrm{s}$, jet spacing $1.35 \mathrm{~cm}$.

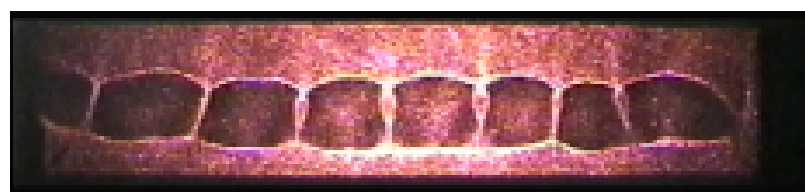

Figure 9(c). Moving tubes, $12.9 \% \mathrm{H}_{2}$, strain rate 75 $\mathrm{s}^{-1}, V_{\text {upper }}=58.6 \mathrm{~cm} / \mathrm{s} V_{\text {lower }}=36.6 \mathrm{~cm} / \mathrm{s}$. (Tubes move from center towards outer edges).

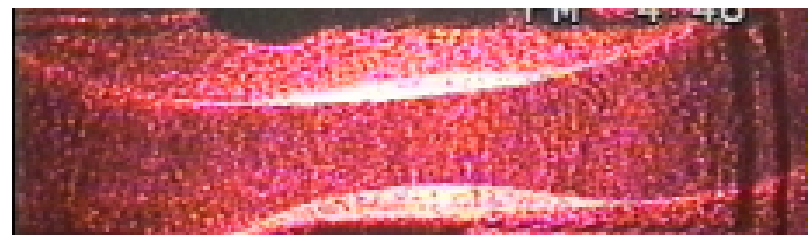

Figure $9(d)$. Moving tubes, orthogonal view, $12.9 \%$ $H_{2}$, strain rate $71 \mathrm{~s}^{-9}, V_{\text {upper }}=58.6 \mathrm{~cm} / \mathrm{s} \quad V_{\text {lower }}=36.6$ $\mathrm{cm} / \mathrm{s}$, jet spacing $1.35 \mathrm{~cm}$.

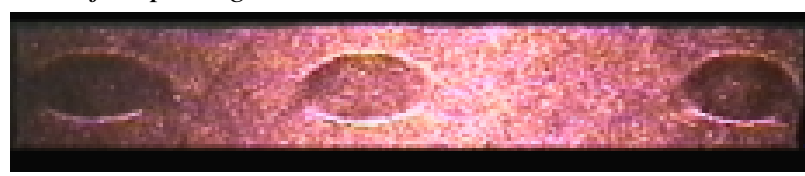

Figure 9(e). Three stationary tubes, $13.9 \% \mathrm{H}_{2}$, strain rate $50 \mathrm{~s}^{-1}$, jet spacing $0.95 \mathrm{~cm}$.

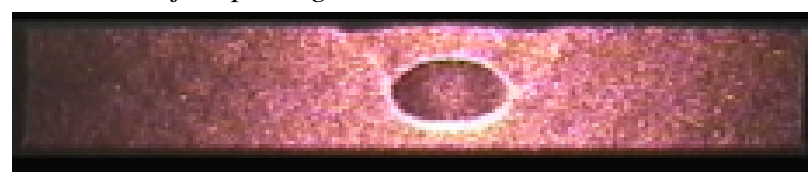

Figure $9(f)$. Single stationary tubes, $12.7 \% \mathrm{H}_{2}$, strain rate $100 \mathrm{~s}^{-1}$, jet spacing $0.95 \mathrm{~cm}$.

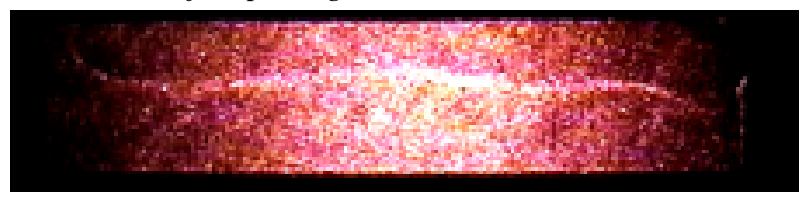

Figure $9(\mathrm{~g})$. Plane flame near extinction, $12.7 \% \mathrm{H}_{2}$, strain rate $120 \mathrm{~s}^{-1}$.

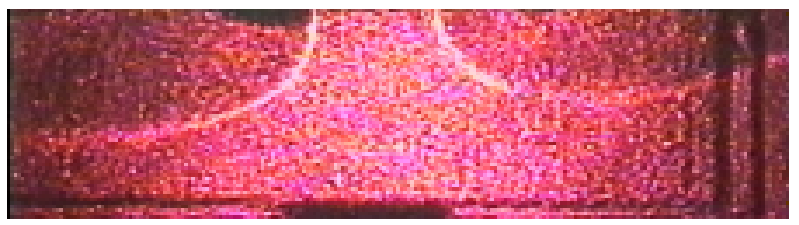

Figure 9(h). Orthogonal view of plane flames near extinction, $11.6 \% \mathrm{H}_{2}$, strain rate $71 \mathrm{~s}^{-1}, V_{\text {upper }}=58.6$ $\mathrm{cm} / \mathrm{s} V_{\text {lower }}=36.6 \mathrm{~cm} / \mathrm{s}$, jet spacing $1.35 \mathrm{~cm}$.

\section{$\underline{\text { Summary and conclusions }}$}

The stability premixed and nonpremixed $\mathrm{H}_{2}-\mathrm{O}_{2}-\mathrm{N}_{2}$ flames in a counterflow geometry was examined. A wide range of flame structures were observed, particularly close to extinction limits. These structures result from the interactions of several effects including diffusive-thermal instability, flame stretch, heat loss to burner exits and the shear layer between the jets and ambient atmosphere. 
In future work an inert co-flow will be added to both jets in order to suppress the shear layer between the jets and the ambient atmosphere, as well as suppress any possible mixing of the fuel jet with ambient air in the case of nonpremixed flames. Smaller width jets will be used to determine if higher $\sigma$ can be obtained without a transition to turbulence, and thereby examine instabilities along a larger region of the upper (stretch-induced) extinction branch. Also, LDV will be employed to measure local flow velocities, and planar laser-induced fluorescence will be used for more quantitative determination of flame structure.

Another line of investigation will consider high Lewis number flames, since theory predicts the existence of varying instability modes for both premixed and nonpremixed flames. The high-Le instability modes of unstretched premixed flames is well known. ${ }^{19}$ Premixed flames are known to have these instabilities in freely propagating flames in tubes $^{48}$ and preliminary evidence suggests their existence in counterflows. $^{29}$ We are unaware of any studies of the instability behavior of high-Le counterflow premixed flames, but Farmer and Ronney ${ }^{49}$ have shown that for outward propagating spherical flames (which are positively stretched, as counterflow flames are), stretch encourages instability. For nonpremixed flames, no experimental results are available but Kim and Lee ${ }^{13}$ have predicted that stretch enables pulsations and travelling waves in nonpremixed flames near extinction.

\section{$\underline{\text { Acknowledgments }}$}

This work was supported by the NASA Glenn Research Center under grant NAG3-2124. The authors thank Drs. John Buckmaster, John Dold, Jong-Soo Kim and Moshe Matalon for helpful discussions.

\section{$\underline{\text { References }}$}

${ }^{1}$ Markstein, G. H. (1953). Instability phenomena in combustion waves. Fourth Symposium (International) on Combustion, Williams and Wilkins, Baltimore, 1953, pp. 43-49.

${ }^{2}$ Markstein, G. H. (1964). Non-Steady Flame Propagation, Pergamon.

${ }^{3}$ Sivashinsky, G. I. (1977). Diffusional-thermal theory of cellular flames. Combustion Science and Technology 15, 137-146.

${ }^{4}$ Mitani, T. and Williams, F. A. (1980). Studies of cellular flames in hydrogen-oxygen-nitrogen mixtures. Combust. Flame 39, 169-190.

${ }^{5}$ Ronney, P. D. (1990). Near-Limit Flame Structures at Low Lewis Number. Combust. Flame, 82, 1-14.
${ }^{6}$ Gorman, M., el-Hamdi, M., and Robbins, K. (1994). Experimental observation of ordered states of cellular flames. Combust. Sci. Tech. 98, 37-45.

${ }^{7}$ Ishizuka, S. and Tsuji, H. (1980). An experimental study of effect of inert gases on extinction of laminar diffusion flames. Eighteenth Symposium (International) on Combustion, Combustion Institute, p. 695.

${ }^{8}$ Chen, R. H., Mitchell, G. B. and Ronney, P. D. (1992). Diffusive-thermal instability and flame extinction in non-premixed combustion. TwentyFourth International Symposium on Combustion, Combustion Institute, Pittsburgh, p. 213.

${ }^{9}$ Kim, J. S., Williams, F. A., Ronney, P. D. (1996). Diffusional-thermal instability of diffusion flames. $J$. Fluid Mech. 327, 273-302.

${ }^{10}$ Sivashinsky, G. I., Law, C. K. and Joulin, G. (1982). On stability of premixed flames in stagnationpoint flow. Combustion Science and Technology 28, 155-159.

${ }^{11}$ Matalon. M. and Erneux, T. (1984). Expanding flames may delay the transition to cellular structures. SIAM J. Appl. Math. 44, 734-744.

${ }^{12}$ Buckmaster, J. D. and Short, M. (1999). Cellular instabilities, sub-limit structures and edge-flames in premixed counterflows. Combust. Theory Modelling 3, 199-214.

${ }^{13}$ Kim, J. S. and Lee, S. R. (1999). Diffusionalthermal instability in strained diffusion flames with unequal Lewis numbers. Combust. Theory Modelling 3, 123-146.

${ }^{14}$ Thatcher, R. W., Dold, J. W., Cooper, M. (1999). Edges of flames that dont exist. Submitted to Combustion Theory and Modelling. (See also Proceedings of the Seventh SIAM International Conference on Numerical Combustion, York, England, March 30 - April 1, 1998, p. 107.)

${ }^{15}$ Daou, J. and Lin, A. (1998). The role of unequal diffusivities in ignition and extinction fronts in strained mixing layers. Combust. Theory Modelling 2, 449477.

${ }^{16}$ Daou, J. and Lin, A. (1999). Ignition and extinction fronts in counterflowing premixed reactive gases. Combust. Flame. 118, 479-488.

${ }^{17}$ Abdel-Gayed, R. G., Bradley, D., Hamid, M. N., Lawes, M. (1984). Lewis number effects on turbulent burning velocity. Twentieth Symposium (International) on Combustion, Combustion Institute, Pittsburgh, pp. 1725-1735.

${ }^{18}$ Wu, M.-S., Kwon, S., Driscoll, J. F., Faeth, G. M. (1990). Turbulent premixed hydrogen/air flames at 
high Reynolds numbers. Combust. Sci. Tech. 73, 327350 .

${ }^{19}$ Joulin, G. and Clavin, P. (1979). Linear stability analysis of nonadiabatic flames: diffusional-thermal model. Combust. Flame 35, 139.

${ }^{20}$ Buckmaster, J. D. and Ludford, G. S. S. (1983). Lectures on Mathematical Combustion, Society for Industrial and Applied Mathematics, Philadelphia, pp. 62-65.

${ }^{21}$ Ronney, P. D., Wu, M. S., Pearlman, H. G. and Weiland, K. J. (1998). Experimental study of flame balls in space: preliminary results from STS-83. AIAA J. 36, 1361-1368.

${ }^{22}$ Zeldovich, Ya. B. (1944). Theory of Combustion and Detonation of Gases, Academy of Sciences (USSR), Moscow.

${ }^{23}$ Joulin, G. (1987). Preferential diffusion and the initiation of lean flames of light fuels," SIAM J. Appl. Math. 47, 998-1016.

${ }^{24}$ Buckmaster, J. D., Smooke, M. and Giovangigli, V. (1993). Analytical and numerical modelling of flameballs in hydrogen-air mixtures. Combust. Flame 94, 113-124.

${ }^{25}$ Ronney, P. D., Whaling, K. N., Abbud-Madrid, A., Gatto, J. L., Pisowicz, V. L. (1994). Stationary Premixed Flames in Spherical and Cylindrical Geometries. AIAA J. 32, 569-577.

${ }^{26}$ Williams, F. A. (1985). Combustion Theory, 2nd ed., Benjamin-Cummins.

${ }^{27}$ Ishizuka, S., Miyasaka, K., Law, C. K. (1982). Effects of heat loss, preferential diffusion, and flame stretch on flame-front instability and extinction of propane-air mixtures. Combust. Flame 45, 293-308.

${ }^{28}$ Ishizuka, S. and Law, C. K. (1982). An experimental study on extinction and stability of stretch premixed flames. Nineteenth Symposium (International) on Combustion, Combustion Institute, pp. 327-335.

${ }^{29}$ Liu, J.-B. and Ronney, P. D. (1999). Premixed edge-flames in spatially varying straining flows. Combust. Sci. Tech. 144, 21-46.

${ }^{30}$ Linan, A. (1974). The asymptotic structure of counterflow diffusion flames for large activation energies. Acta Astronaut. 1, 1007-1039.

${ }^{31}$ Kim , J. S. (1997). Linear analysis of diffusionalthermal instability in diffusion flames with Lewis number close to unity. Combust. Theory Modelling 1, 13-40.

${ }^{32}$ Kim, J. S. (1996). Diffusional-thermal instability of diffusion flames in the premixed-flame regime. Combust. Sci. Tech. 118, 27-48.
${ }^{33}$ Shay, M. L. and Ronney, P. D. (1998). Nonpremixed flames in spatially-varying straining flows. Combustion and Flame 112, 171-180.

${ }^{34}$ Ashurst, W. T., Kerstein, A. R., Kerr, R. M. and Gibson, C. H. (1987). Alignment of vorticity and scalar gradient with strain rate in simulated NavierStokes turbulence. Phys. Fluids 30, 2343.

${ }^{35}$ Garside, J. E., Jackson, B. (1953). The formation and some properties of polyhedral burner flames. Fourth Symposium (International) on Combustion, Williams and Wilkins, Baltimore, pp. 545-552.

${ }^{36}$ Dongworth, M., Melvin, A. (1976). The transition to instability in a steady hydrogen-oxygen diffusion flame. Combust. Sci. Technol. 14, 177-182.

${ }^{37}$ Vedarajan, T. G. and Buckmaster, J. D. (1998). Edge-flames in homogeneous mixtures. Combust. Flame 114, 267.

${ }^{38}$ Seshadri, K. and Williams, F. A. (1978). Laminar flow between parallel plates with injection of a reactant at high Reynolds number. International Journal of Heat and Mass Transfer 21, 251.

${ }^{39}$ Vagelopoulos, C. M., Egolfopoulos, F. N., Law, C. K. (1994). Further considerations on the determination of laminar flame speeds with the counterflow twinflame technique. Twenty-Fifth Symposium (International) on Combustion, Combustion Institute, p. 1341.

${ }^{40}$ Bradley, D. (1992). How fast can we burn? TwentyFourth Symposium (International) on Combustion, Combustion Institute, Pittsburgh, p. 247.

${ }^{41}$ Buckmaster, J. D. (1997). The effects of radiation on stretched flames, Combust. Theory Modeling 1, 1 -11.

${ }^{42}$ Ju, Y., Guo, H., Liu, F., Maruta, K. (1999). Effects of the Lewis number and radiative heat loss on the bifurcation of extinction of $\mathrm{CH}_{4}-\mathrm{O}_{2}-\mathrm{N}_{2}-\mathrm{He}$ flames. $J$. Fluid Mech. 379, 165-190.

${ }^{43}$ Guo, H., Ju, Y., Maruta, K., Niioka, T., Liu, F. (1997). Radiation extinction limit of counterflow premixed lean methane-air flames. Combust. Flame 109, 639-646.

${ }^{44}$ Ronney, P. D. (1998). Understanding Combustion Processes Through Microgravity Research. TwentySeventh International Symposium on Combustion, Combustion Institute, Pittsburgh, pp. 2485-2506.

${ }^{45}$ Margolis, S. B. (1980). Bifurcation phenomena in burner-stabilized premixed flames. Combust. Sci. Tech. 22, 143-169.

${ }^{46}$ Maruta, K., Yoshida, M., Guo, H., Ju, Y., Niioka, T. (1998). Extinction of low-stretched diffusion flame in microgravity. Combust. Flame 112, 181-187. 
${ }^{47}$ Egolfopoulos, F. N. (1994). Geometric and Radiation Effects on Steady and Unsteady Strained Laminar Flames. Twenty-Fifth Symposium (International) on combustion, Combustion Institute, Pittsburgh, pp. 1375-1381.

${ }^{48}$ Pearlman, H. G. and Ronney, P. D. (1994). Nearlimit behavior of high Lewis-number premixed flames in tubes at normal and low gravity. Physics of Fluids 6, 4009.

${ }^{49}$ Farmer, J. R., Ronney, P. D. (1990). A numerical study of unsteady nonadiabatic flames. Combust. Sci. Tech. 73, 555-574, 